anales de psicología, 2018, vol. 34, $\mathrm{n}^{\circ} 1$ (january), 108-116 http://dx.doi.org/10.6018/analesps.34.1.259601
(C) Copyright 2018: Editum. Servicio de Publicaciones de la Universidad de Murcia. Murcia (Spain) ISSN print edition: 0212-9728. ISSN web edition (http://revistas.um.es/analesps): 1695-2294

\title{
Corporal punishment by parents and child-to-parent aggression in Spanish adolescents
}

\author{
Joana Del Hoyo-Bilbao ${ }^{*}$, Manuel Gámez-Guadix ${ }^{2}$, and Esther Calvete ${ }^{1}$ \\ 1 University of Deusto (Spain). \\ 2 Autonomous University of Madrid (Spain).
}

\begin{abstract}
Título: Castigo físico de padres y madres a hijos e hijas y Violencia filioparental entre adolescentes españoles

Resumen: La Violencia Filio-parental (VFP) es un problema social que está recibiendo gran atención, debido al aumento de su frecuencia y a las consecuencias para sus víctimas. El principal objetivo del estudio fue evaluar las relaciones longitudinales entre recibir castigo físico $(\mathrm{CF})$ y perpetrar VFP física y psicológica en adolescentes. Un segundo objetivo fue estudiar si la relación entre el CF y la VFP es moderada por el contexto parental en el que el CF es usado, la edad o el género del adolescente. Un total de 896 adolescentes (527 chicas) con edades comprendidas entre 13 y 19 ( $M=$ 14.88; $D T=1.021)$ completaron instrumentos de VFP, CF y contexto parental positivo en el Tiempo1 y seis meses después. Los resultados de los análisis mostraron que el CF en el Tiempo1 predijo la perpetración de VFP psicológica en el Tiempo2. Ninguna variable (contexto parental positivo, edad, sexo) moderó la relación entre el CF y la VFP. A su vez, la VFP psicológica en el Tiempo1 predijo un incremento de la VFP física en el Tiempo2. Estos resultados sugieren que, el CF está relacionado con la VFP con independencia del contexto en el que es usado, la edad o el sexo del menor.
\end{abstract}

Palabras clave: Violencia Filio-parental, castigo físico, adolescente, contexto parental positivo, agresión.

\section{Introduction}

The relationships between parents and their children can occasionally escalate to high levels of family conflict (Omer, 2004). Several parent-child relationships transcend the limits of "conflictive relationships" to become "abusive relationships" of children to parents. These relationships have been defined as child-to-parent aggression (CPA) (Cottrell \& Monk, 2004). Although CPA is not a new problem, as indicated in research from the 1980s (Harbin \& Madden, 1979; Peek, Fisher, \& Kidwell, 1985), there is still scarce empirical evidence available (Aroca-Montolío, Lorenzo-Modelo, \& Miró-Pérez, 2014; Hong, Kral, Espelage, \& Allen-Meares, 2012; Romero, Melero, Cánovas, \& Antolín, 2007; Walsh \& Krienert, 2007). However, in recent years, the number of international studies focusing on CPA is increasing (Calvete, Orue, Gámez-Guadix, \& Bushman, 2015; Hong et al., 2012), as a result of the considerable interest that CPA is receiving because of the increasing frequency (Coogan, 2011; International News Agency (EFE), 2009) as well as the serious consequences for its victims (Paterson, Luntz, Perlesz, \& Cotton, 2002).

The severity of the problem and the increasing number of cases emphasize the need to understand the factors involved in the development of CPA. CPA, like other types of

* Correspondence address [Dirección para correspondencia]

Joana Del Hoyo-Bilbao. Psychology Department of Personality, Assessment and Treatment. Avenida de las Universidades 24, -1 Floor. University of Deusto, 48080 Bilbao (Spain).

E-mail: joana.delhoyo@deusto.es
Abstract: Child-to-parent aggression (CPA) is a social problem that is receiving much attention because of the increasing frequency and the consequences for its victims. The primary aim of this study was to assess the longitudinal relationship between receiving corporal punishment $(\mathrm{CP})$ and perpetrating physical and psychological CPA in adolescents. The second aim was to investigate whether receiving $\mathrm{CP}$ in a positive parenting context, age and sex of the adolescent, moderated the relationship between $\mathrm{CP}$ and CPA. A total of 896 adolescents (527 girls) between the ages of 13 and $19(M=14.88 ; S D=1.021)$, completed measures of CPA, CP and positive parenting at Time 1 and six months later. The results showed that $\mathrm{CP}$ at Time 1 predicted an increased psychological CPA at Time 2. None of the variables (positive parenting, age and sex) moderated the relationship between CP at T1 and CPA at T2. These results suggest that CP is related to CPA regardless of the context in which it is used, the age or sex of the child.

Keywords: Child-to-parent aggression; corporal punishment; adolescent; positive parenting, aggression.

family violence, has remained hidden (Robinson, Davidson, \& Drebot, 2004). Familiar factors are important aspects for understanding CPA (Calvete et al., 2015; Gámez-Guadix, Jaureguizar, Almendros, \& Carrobles, 2012; Hong et al., 2012). In the last three decades, several authors have emphasized the importance of evaluating the disciplinary practices of parents regarding the occurrence of CPA (Calvete, Orue, Gámez-Guadix, Del Hoyo-Bilbao, \& López de Arroyabe, 2015; Cottrel, 2005; Harbin \& Madden, 1979; Ibabe, 2015). Although recent reviews have indicated mixed results (Hong et al., 2012), several studies have shown that parenting practices are related with CPA (Calvete, Orue, \& Sampedro, 2011; Calvete et al., 2015; Gámez-Guadix \& Calvete, 2012; Ibabe, 2015; Pagani, Tremblay, Nagin, Zoccolillo, Vitaro, \& McDuff, 2009).

Regarding parental practices, the strategy that has received most empirical attention is corporal punishment (CP). $\mathrm{CP}$ is likely to be the most controversial issue related to parental discipline (Berlin et al., 2009; Gámez-Guadix, Straus, Carrobles, Muñoz-Rivas, \& Almendros, 2010). CP is defined as the use of physical force with the intention of causing pain or discomfort in a child to correct or control the child's behavior (Straus, 2001). In Spain, despite the scarcity of the literature that has focused on the consequences of $\mathrm{CP}$, the European DAPHNE project indicated that between 50 and $60 \%$ of European families justify corporal punishment (Red de Universidades Valencianas para el fomento de la Investigación, el Desarrollo y la Innovación, 2013), and more than $60 \%$ reported having received CP in childhood (GámezGuadix, Straus et al., 2010). The prevalence of the acceptance and use of CP in Spain represent a problem be- 
cause empirical evidence has shown the link between CP and negative consequences in the short and long term. For instance, CP has been associated with a greater likelihood of aggressive and antisocial behavior (Berlin et al., 2009; Gámez-Guadix, Straus, \& Hersberguer, 2011; Straus, 2001, 2008; Gámez-Guadix, Straus et al., 2010; Simons, Simons, \& Wallace, 2004). Paolucci and Violato (2004), in a metaanalysis of 70 studies, found that children who had received CP demonstrated significantly more behavioral problems. Additionally, in a meta-analysis of 88 empirical studies, Gershoff (2002) reported a relationship between CP and numerous negative consequences, including externalizing and internalizing problems in children. Furthermore, in a recent meta-analysis in which 45 longitudinal studies were analyzed, Ferguson (2013) found that CP was associated with internalizing and externalizing negative consequences, as well as with worse cognitive efficiency, although the effect size of the relationship was small.

As previously indicated, the available results are unclear about the relationship between CPA and disciplinary practices. This also occurs in the available evidence between CPA and CP. For example, in two studies, it was found that CP was positively associated with CPA (Gámez-Guadix et al., 2012; Pagani et al., 2009). Similarly, in a recent qualitative study of families seeking assistance from a specialized service aimed at treating CPA problems, a high percentage of participants $(67 \%)$ reported the use of CP in their family context (Calvete et al., 2015). However, a correlational study with a community sample of 1427 adolescents found that the use of punishment by the parents, in general, was associated with less aggression in children (Calvete et al., 2011). Nevertheless, the authors of the study concluded that it is not the application of CP what is related to CPA. Adolescents who exercise CPA informed to have been exposed to fewer acts of discipline, including both functional and dysfunctional practices (Calvete et al, 2011).

One likely explanation for these inconsistent results regarding the effects of $\mathrm{CP}$ is the argument that using $\mathrm{CP}$ in a positive parenting context has no negative effects on the child (Benjet \& Kazdin, 2003; Larzerele, 2000). However, in addition to being inconsistent in their conclusions, there are few studies that analyze the moderating role of positive parenting with respect to the effects of CP on children (e.g., Harper, Brown, Arias, \& Brody, 2006). Furthermore, a recent study with a community population that analyzed the relationship between $\mathrm{CP}$ and behavioral problems in the long term demonstrated that the negative effects of $\mathrm{CP}$ were not moderated by positive parenting (Gámez-Guadix, Straus et al., 2010). In other words, CP was related to an antisocial orientation in children regardless of whether CP was administered in a context of positive parenting.

Therefore, given the previous inconsistent results regarding the consequence of $\mathrm{CP}$ and its habitual use and justification among parents, it is important to analyze its relationship with CPA. Additionally, the role of CP may be moderated not only by positive parenting but also by the adolescent's age (Larzerele, 2000). Larzerele (2000) carried out a literature review in which he found that, when $\mathrm{CP}$ is administered at younger ages, it does not have negative consequences. Another important aspect for understanding the possible consequences of administrating CP is the sex of the child. It seems that the child's sex does not moderate the relationship between CP and externalizing problems, as was concluded in a transversal study conducted in the Spanish population (Gámez-Guadix, Straus et al., 2010). Furthermore, there is no agreement about the role of the child's sex and CPA. Although some studies have indicated that there are no sex differences (Gámez-Guadix \& Calvete, 2012; Pagani et al., 2004, 2009), other studies have suggested that girls are more likely to have higher scores on psychological CPV (e.g., Calvete et al., 2015; Calvete et al., 2013; Jaureguizar, Ibabe, \& Straus, 2013) and boys on physical CPV (e.g., Brezina, 1999; Calvete et al., 2011; Calvete et al., 2015; Ibabe, Jaureguizar, \& Bentler, 2013).

Moreover, the majority of the studies that focused on the analysis of family strategies and CPA are cross-sectional (for exceptions, see Calvete et al., 2015; Brezina, 1999), which is a major limitation of the research to date because it does not allow for the establishing of longitudinal relationships between variables (Calvete, Gámez-Guadix, \& Orue 2014; Gámez-Guadix et al., 2012).

From the results of the available literature, the present study has the following aims. The first aim of this study was to analyze the longitudinal relationship between CP and CPA (both physical and psychological) in an adolescent Spanish sample. Because previous studies have reported a crosssectional relationship between severe discipline and CP with CPA (Gámez-Guadix et al., 2012; Pagani et al., 2009), we hypothesized that receiving $\mathrm{CP}$ within the last year will increase the likelihood of child-to-parent aggression perpetrated 6 months later. The second aim of this study was to analyze the moderating role of positive parenting in the relationship between CP and CPA. Despite the controversy regarding the consequences of CP (e.g., Benjet \& Kazdin, 2003), drawing on the findings of studies carried out in the Spanish context on the moderating role of positive parenting in the relationship of CP and other externalizing behaviors (Gámez-Guadix, Straus et al., 2010), we hypothesized that positive parenting would not moderate the relationship between CP and future CPA. The third aim of the study was to analyze whether sex moderates the association between $\mathrm{CP}$ and CPA. As in the previous point, there are inconsistencies in previous studies regarding the role of the child's sex in CPA (e.g., Gámez-Guadix \& Calvete, 2012; Jaureguizar, Ibabe, \& Straus, 2013). Nevertheless, attending to one of the few studies conducted in the Spanish population in which sex did not moderate the association between CP and behavior problems in adolescents, we hypothesized that the child's sex would not moderate the predictive relationship between CP and future CPA (Gámez-Guadix et al., 2010). Finally, the fourth aim of the study was to analyze whether the adolescent's age moderates the predictive association between 
CP and CPA. Given the absence of previous studies that analyzed the moderating role of adolescents' age on this relationship, we analyzed this issue exploratorily.

\section{Method}

\section{Participants}

The initial sample consisted of 1014 adolescents. The participants were students from 12 secondary schools. Seven of twelve schools were private, and six of twelve schools were religious. The schools were located in nine different neighborhoods of Bizkaia (Basque Country, Spain). The schools were chosen from all the schools of Bizkaia using random cluster sampling. Adolescents of $3^{\text {rd }}$ and $4^{\text {th }}$ grade of secondary compulsory education and of $1^{\text {st }}$ and $2^{\text {nd }}$ grade of high school were evaluated. Specifically, $48.3 \%$ of the adolescents were in $3^{\text {rd }}$ grade, $23.5 \%$ were in $4^{\text {th }}$ grade, $26.2 \%$ were in $1^{\text {st }}$ grade of high school, and $2 \%$ were in $2^{\text {nd }}$ grade of high school. The final sample included 896 adolescents $(n=$ 369 boys and 527 girls) between the ages of 13 and $19(M=$ 14.88; $S D=1.021$ ), who completed the measures both at Time 1 (T1) and at Time 2 (T2). The attrition rate was $11.6 \%$. The main reason was that between $\mathrm{T} 1$ and $\mathrm{T} 2$ the adolescents moved to the next school year, so many had finished high school by the time T2 data were collected. Most of the parents were married $(82.3 \%)$, whereas $15.8 \%$ of the parents were divorced $(13.4 \%)$ or separated (2.4\%). Only $2.1 \%$ of the participants lived with one parent, who was either a widow/er $(1.7 \%)$ or single $(0.4 \%)$. Most adolescents' parents were Spanish (88\%), whereas 1\% were from Eastern Europe, 8.5\% from Latin America, 1\% from Morocco, and $1.5 \%$ from other locations. The participants' socioeconomic levels were determined using the criteria recommended by the Working Group of the Spanish Society of Epidemiology and the Spanish Society of Family Medicine and Community (2000). Adolescents completed the items concerning the professional occupation of their mother and father separately. The mean of the two professional occupations was calculated to reflect the socioeconomic reality. The socioeconomic levels had the following distributions: $13 \%$ low, 32\% medium-low, 30.8\% medium, 14.6\% medium-high, and 9.6\% high.

\section{Measures}

Child-to-parent aggression. CPA was measured using the Child-to-Parent Aggression Questionnaire (CPAQ) (Calvete et al., 2013). The questionnaire consists of 20 items, 10 referring to the father and 10 referring to the mother. Of the 10 items relevant to each parent, three items assess physical aggression (e.g., hitting with something that could hurt), and seven items assess psychological aggression (e.g., insulting the parent or threatening to hit the parent). The adolescents reported how often they had performed each of the aggressive acts against their father and their mother within the last year $(0=$ never, $1=$ once or twice; $2=3$ to 5 times; $3=6$ or more times). CPAQ has demonstrated excellent psychometric proprieties in Spanish samples, including validity and reliability (Calvete et al., 2013). In this sample, the alpha coefficients were .84 and .80 for the physical subscale and .89 and .89 for the psychological subscale at T1 and T2, respectively.

Corporal Punishment. CP was measured using the Corporal Punishment subscale of the Dimensions of Discipline Inventory (DDI) (Straus \& Fauchier, 2007). The subscale has three questions: how often did your parents shake or grab you to get their attention; how often did your parents spank, slap, smack, or swat you; how often did your parents use a paddle, hairbrush, belt, or other object to punish you. The adolescents reported how often their parents did those things within the last year. The 6 response categories ranged from $\mathrm{N}$ (Never) to 5 (more than 20 times). The DDI has demonstrated good construct validity and acceptable internal consistence reliability in the Spanish sample (Gámez-Guadix, Orue et al., 2010). In this sample, the alpha coefficient was .72 at T1.

Positive Parenting. The Positive Parenting scale of the DDI was used (Straus \& Fauchier, 2007; see Gámez-Guadix, Straus et al., 2010). This scale included the following four questions: how often did your parents do or say things to show that they loved and supported you; how often did your parents explained their actions taken to correct you; how often did you feel encouraged, supported; and how often did your parents check on you so that they could tell you that you were doing a good job (Gámez-Guadix, Straus et al., 2010). The adolescents reported how often their parents did those things within the last year. The 6 response categories ranged from $\mathrm{N}$ (Never) through 5 (more than 20 times). In this sample, the alpha coefficient was .84 at T1.

\section{Procedure}

The schools were chosen by random cluster sampling. A list of possible schools of Bizkaia that met the age criteria needed to carry out the study was created. The schools were invited to participate in the study. When they agreed, researchers invited all students between 13 and 19 years to participate. We contacted the adolescents' parents to obtain their passive informed consent. None of the parents refused to allow their children to participate in the study; all of the adolescents agreed to participate in the study. At the beginning of the study, the adolescents were informed that their participation was part of a study of risk factors for aggressive behavior in adolescence and adolescent relationships, including relationships with their parents. The participants were informed that their participation was voluntary and anonymous and that their responses were confidential and would only be read by the investigation team. The parents received similar information. The data were collected on two occasions with a 6-month interval. We employed a code for each participant for subsequent pairing of the measures. All of the data were processed under the code of ethics in research and were kept confidential. The Ethics Committee of University of Deusto revised and approved this study. 


\section{Results}

\section{Descriptive Analyses}

First, the prevalence of CPA within the last year was calculated. The total prevalence for psychological CPA was $91.2 \%$ at $\mathrm{T} 1$ and $90.9 \%$ at T2. For physical CPA, the total prevalence was $9 \%$ at $\mathrm{T} 1$ and $8.2 \%$ at $\mathrm{T} 2$. To estimate the total psychological CPA and total physical CPA, we included all the adolescents who admitted to at least one act of these categories. As these percentages also included cases of a single incident occurring during the past year, this may lead to overestimation of the prevalence of CPA. Therefore, we estimated severe forms of CPA, following the procedure indicated by the authors of the questionnaire (Calvete et al., 2013). Incidents of severe psychological CPA included adolescents who reported performing threatening behavior, insulting, blackmailing, taking money without permission, doing something to annoy the parent, and disobeying a parent's important request more than 6 times within the past year (Calvete et al., 2013). Thus, the prevalence of severe psychological CPA was $14 \%$ at $\mathrm{T} 1$ and $13.1 \%$ at T2. To estimate severe physical CPA, the authors of questionnaire proposed to calculate the percentage of adolescents who reported hav- ing committed an act of physical aggression against their parents at least 3-5 times in the past year. In this study, the prevalence of severe physical CPA was $1.8 \%$ at T1 and $2.8 \%$ at T2.

Regarding CP, to consider the existence of CP, we used the criteria indicated by the questionnaire's authors (Straus \& Fauchier, 2007). They consider the existence of CP when the adolescents reported their parents' shaking or grabbing them to get their attention; spanking, slapping, smacking, or swatting them; using a paddle, hairbrush, belt, or other object to punish them at least once within the past year $(1,2,3,4$, and 5 on the response scale). Thus, $43 \%$ of the adolescents admitted that their parents used CP (e.g., spanking, slapping, smacking, or swatting).

Table 1 shows the correlations and descriptive statistics (mean and standard deviation values) for the variables in the study. As shown, the highest correlations are established between the same variable at T1 and T2, indicating a high stability between CPA from T1 to T2. Additionally, the correlation between psychological CPA and physical CPA at the same time point (e.g., at T1) indicate coexistence between the two types of violence. CP at T1 showed a positive and statistically significant relationship relevant to all types of CPA at both T1 and T2 (Table 1).

Table 1. Pearson correlations and descriptive statistics (means and standard deviations) for the variables in this study.

\begin{tabular}{|c|c|c|c|c|c|c|c|}
\hline & 1 & 2 & 3 & 4 & 5 & 6 & 7 \\
\hline 1. Psychological CPA T1 & 1 & & & & & & \\
\hline 2. Psychological CPA T2 & $.78^{* *}$ & 1 & & & & & \\
\hline 3. Physical CPA T1 & $.39 * *$ & $.38 * *$ & 1 & & & & \\
\hline 4. Physical CPA T2 & $.40^{* *}$ & $.41^{* *}$ & $.57 * *$ & 1 & & & \\
\hline 5. Positive Parenting & $-.06^{*}$ & $-.12^{* *}$ & $-.09 * *$ & $-.12 * *$ & 1 & & \\
\hline 6. Corporal punishment & $.39 * *$ & $.38^{* *}$ & $.26^{* *}$ & $.28^{* *}$ & -.05 & 1 & \\
\hline 7. Age & .02 & .06 & -.00 & .03 & -.05 & $-.08 *$ & 1 \\
\hline 8. Sex $(-1=$ girl, $1=$ boy $)$ & $-.23 * *$ & $-.26 * *$ & $-.07 *$ & $-.07 *$ & -.03 & -.03 & .03 \\
\hline Mean & .58 & .57 & .04 & .05 & 2.66 & -.17 & 14.95 \\
\hline Standard Deviation & .51 & .51 & .19 & .20 & 1.68 & 1.04 & 1.19 \\
\hline
\end{tabular}

Note. Range of scores: CPA (Child-to-parent aggression): from 0 (never) to 3 (6 or more times); Positive Parenting: N (never) to 5 (more of 20 times); Corporal punishment: $\mathrm{N}$ (never) to 5 (more of 20 times). $* p<.05 ; * *<<.01$.

\section{Analyses of the relationship between corporal pun- ishment, child-to-parent violence and the interaction of age, sex and positive parenting}

To analyze the relationships between the variables in the model, we used the statistical software EQS 6.1 (Bentler, 2005). We used the robust maximum likelihood (ML) estimation method with the Satorra-Bentler scale chi-squared (S-B $\chi^{2}$ ) because the data did not meet the assumption of normality (the normalized Mardia's coefficient $=273.58$ ). To study the adequacy of the estimated models, we used the comparative fit index (CFI), the standardized root mean square residual (SRMR), and the root mean square error of approximation (RMSEA). For the NNFI and the CFI, values $>.90$ indicate an acceptable fit. Values on the SRMR and the RMSEA < .08 indicate an acceptable fit (Byrne, 2006; Hu \& Bentler, 1999).
First, we estimated a model that included the analysis of the relationship between age and sex of the child, CP, and positive parenting at T1, and psychological and physical CPA at T2. The child's sex was treated as effect codification (-1 and 1) as recommended by Frazier, Tix, and Barron (2004), because it is a dichotomous variable with mutually exclusive categories. Furthermore, we used three interaction terms, CP $\times$ positive parenting, $\mathrm{CP} \times$ age, and $\mathrm{CP} \times$ sex. To create the interaction terms we followed the steps suggested by Homlbeck (1997). First, continuous variables (e.g., positive parenting) were standardized. Then, the interaction term was created by multiplying $\mathrm{CP}$ with positive parenting and age and sex of the child. The model also included autoregressive paths between the same variable in T1 and T2. This strategy allowed us to analyze whether the change in CPA at T2 could be explained by the remaining predictors once the baseline of this same variable was controlled at T1. 
The estimated initial model showed that several paths were not statistically significant. For example, the relationship between CP at T1 and physical CPA at T2 was not significant. Additionally, the interaction between $\mathrm{CP}$, age and sex of the child and positive parenting at T1 was not related to either physical or psychological CPA at T2. These paths were removed from the model, which was subsequently reestimated with only the significant paths. The fit indices for the estimated final model were adequate: $\chi^{2}(3, N=896)=$ 21.86; $\mathrm{NFI}=.97$; CFI $=.98 ;$ RMSEA $=.058$; and SRMR $=$ .016 .

Figure 1 shows the hypothesized theoretical model and
Figure 2 shows the standardized parameters of the final model. At the longitudinal level, all of the autoregressive paths were high and significant: .55 and .70 (all, $p<.001$ ). Sex, specifically being female, was associated with increased psychological CPA at T2. Furthermore, positive parenting at T1 decreased both types of CPA at T2. Additionally, the results showed that $\mathrm{CP}$ at $\mathrm{T} 1$ significantly predicted increased psychological CPA at T2. This relationship was significant regardless of the child's age or sex and the context of positive parenting in which CP was used. Finally, psychological $\mathrm{CPA}$ at T1 significantly increased physical CPA at T2.

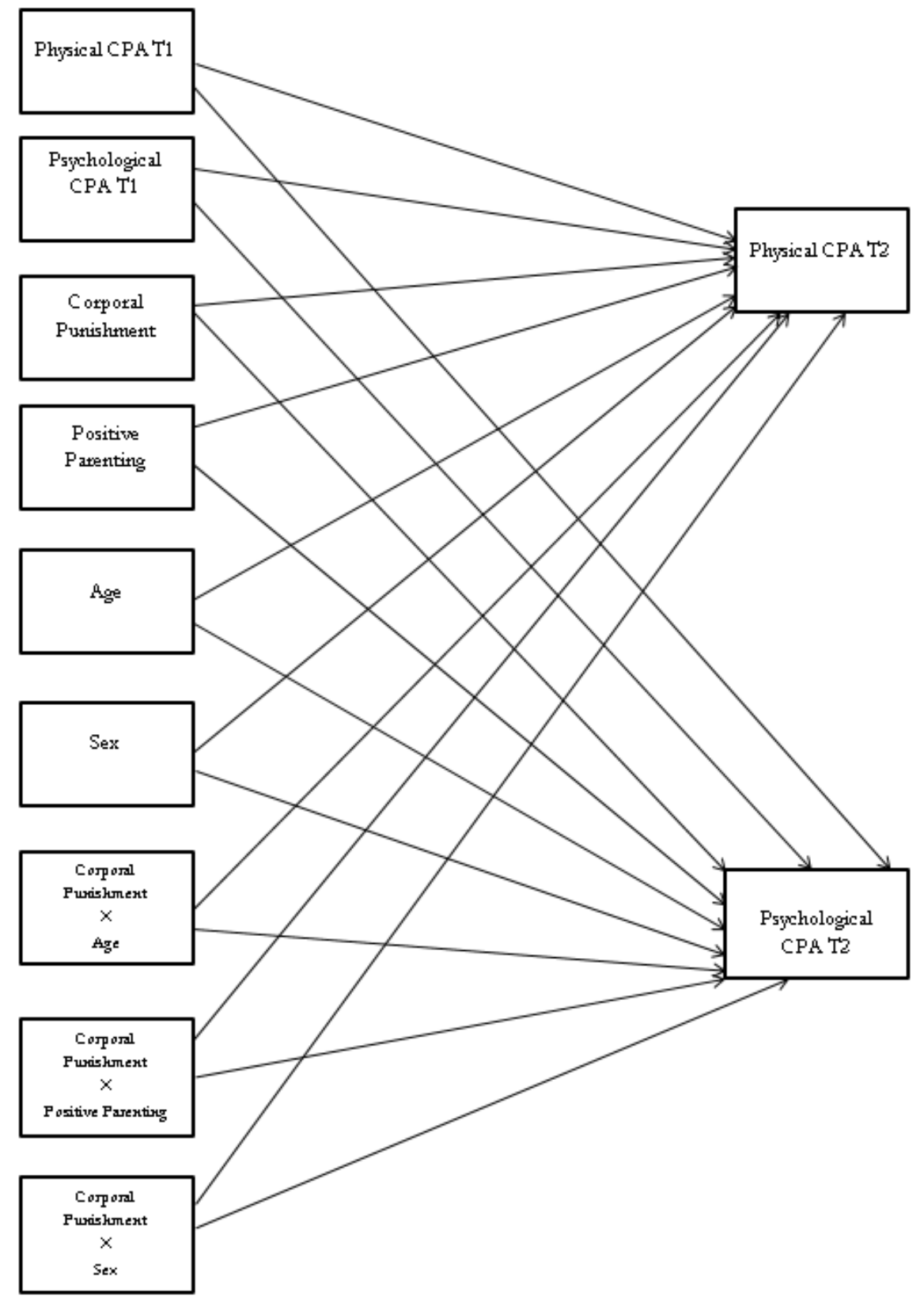

Figure 1. Hypothesized theoretical model. Note. CPA (Child-to-parent aggression). 


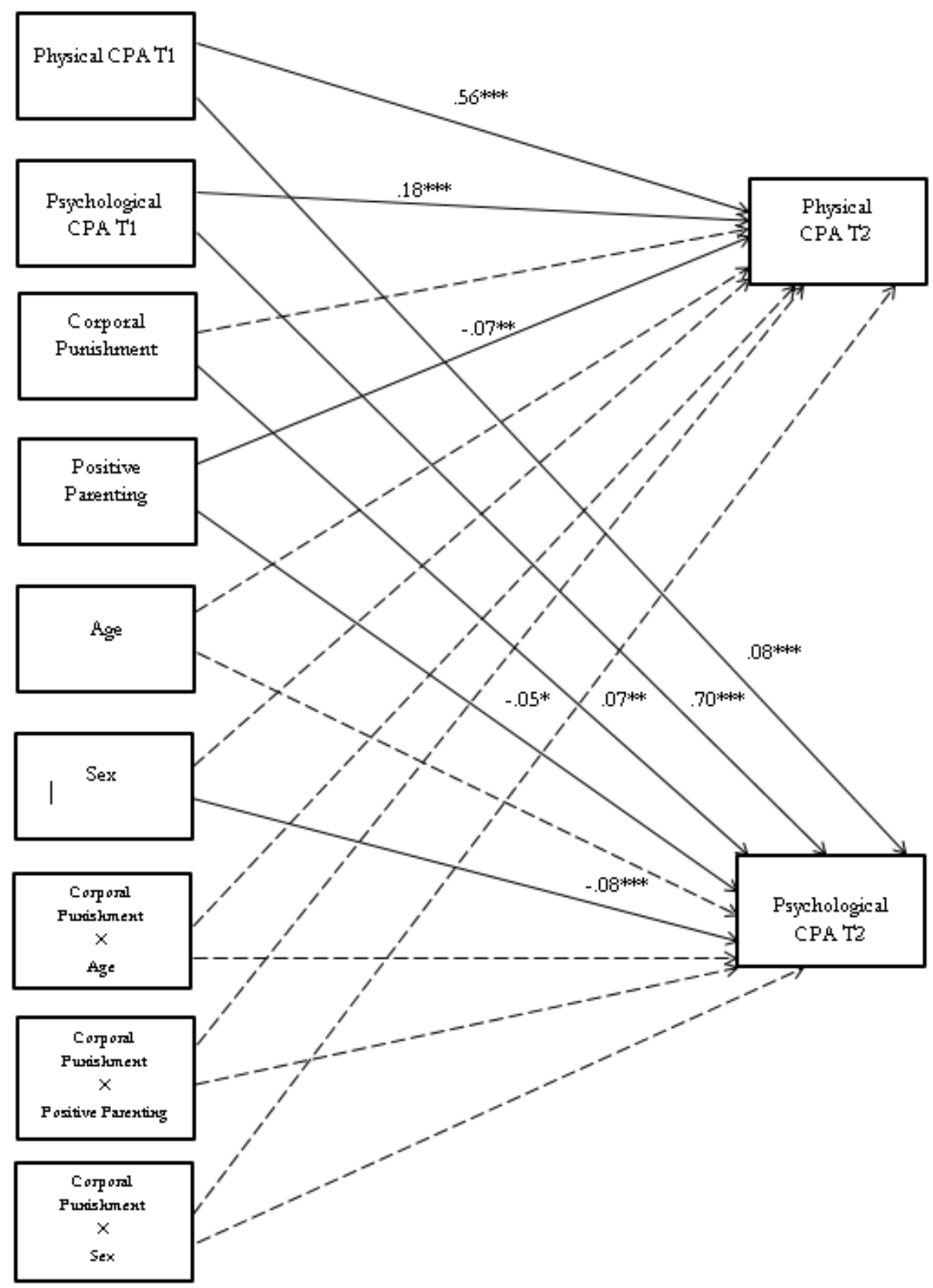

Figure 2. Estimated final model. Note. CPA (Child-to-parent aggression) $* p<.05 ;{ }^{* *} p<.01 ; * * * p<.001$

\section{Discussion}

This study is the first to analyze the longitudinal relationship between receiving CP and perpetration of CPA in adolescents. At the cross-sectional level, CP was associated with both physical and psychological CPA, and at the longitudinal level, CP increased the likelihood of psychological CPA. Positive parenting, sex and age of the child did not moderate the relationship between $\mathrm{CP}$ and CPA. We subsequently discussed the primary theoretical and practical implications of these results.

Consistent with previous studies (Gámez-Guadix, Straus et al., 2010; Straus, 2001), we found high rates of CP by par- ents. Specifically, more than $40 \%$ of the adolescents were physically hit during the previous year. The prevalence rates observed in the present study are lower than those found in previous studies with Spanish samples, which showed prevalence rates of $60 \%$ more than a decade ago (for a revision, see Gámez-Guadix, Straus et al., 2010). This finding could indicate that the use of $\mathrm{CP}$ is decreasing in recent years in Spain. Even so, the rate of CP remains considerably high and should be the focus of educational interventions.

In this study, CPA rates reported by the adolescents were also relevant. In particular, between $8.2 \%$ and $9 \%$ of the adolescents admitted to having perpetrated at least one act of physical aggression against their parents in the assessment 
period. Repeated psychological violence occurred more frequently as between $13.1 \%$ and $14 \%$ of the participants reported performing threatening behavior, insulting, blackmailing, taking money without permission, doing something to annoy the parent and disobeying a parent's important request more than 6 times in the last year. These results are similar to those obtained in several epidemiological studies (Calvete et al., 2013; Calvete et al., 2011; Pagani et al., 2004, 2009; Ulman \& Straus, 2003), and they highlight the magnitude of this modality of family violence in society and the need to develop preventative actions.

$\mathrm{CP}$ was found to be associated with an increased likelihood of psychological CPA over time regardless of whether there was positive parenting. This finding is an important result because it provides empirical evidence contradicting the claim that $\mathrm{CP}$ has no negative consequences when $\mathrm{CP}$ is used by loving and supportive parents (Larzelere, 2000; Ripoll-Núñez \& Rohner, 2006). Overall, the results are congruent with the idea that although CP might produce conformity in the immediate situation, in the long term CP may increase the likelihood of deviance (Straus, 2001; Straus, Sugarman, \& Giles-Sims, 1997), including aggressive behavior and CPA. Several mechanisms, such as less child internalization of the parents' values and low self-control, may explain the relationship between CP and future aggressive behavior in children (Gottfredson \& Hirschi, 1994). Similarly, a child's sex and age do not moderate the relationship between $\mathrm{CP}$ and psychological CPA. Thus, our findings have suggested that CP increases the likelihood of psychological CPA regardless of the sex and age of adolescents.

This study supported the hypothesized relationship between CP and physical CPA at the cross-sectional level but not at the longitudinal level. The type of sample could likely have influenced this result because the levels of physical violence against parents are low in adolescents of community samples, and it may have attenuated the relationship between these variables. The relationship between physical punishment and CPA could emerge with greater time intervals (e.g., one year). Future studies should specify the conditions in which CP and physical CPA are associated.

Importantly, psychological CPA at T1 increased the likelihood of physical CPA at T2, suggesting that CPA is stable over time. Thus, psychological aggressions against parents

\section{References}

Aroca-Montolío, C., Lorenzo-Moledo, M., \& Miró-Pérez, C. (2014). La violencia filio-parental: Un análisis de sus claves. Anales de Psicología, 30(1), 158-171. doi: http://dx.doi.org/10.6018/analesps.30.1.149521

Benjet, C., \& Kazdin, A.E. (2003). Spanking children: The controversies, findings and new directions. Clinical Psychology Review, 23, 197-224. doi:10.1016/S0272-7358(02)00206-4

Bentler, P. M. EQS 6.1 for Windows. Structural equations program manual. Encino, CA: Multivariate Software; 2005.

Berlin, L. J., Ispa, J. M., Fine, M. A., Malone, P. S., Brooks-Gunn, J., BradySmith, C., Ayoub, C., \& Bai, Y. (2009). Correlates and consequences of spanking and verbal punishment for low-income white, AfricanAmerican, and Mexican American toddlers. Child Development, 80, should not be ignored. Instead, these acts could be indicative that something in the family relationships is wrong. Early educational interventions may be sufficient to reorient the patterns of parent-child relationship.

\section{Conclusions, limitations, implications for practice and future prospects of the study}

The results of this study should be interpreted in the context of third important limitations. First, the data were based on information provided by adolescents using self-report measures. It is recommended that future studies include information obtained from parents and use other assessment strategies (e.g., interviews). Second, although this is the first study to analyze the longitudinal relationship between CP and CPA, the relationship between these variables could emerge over periods exceeding six months. Future studies should examine these relationships using other larger time intervals and more time points. It would also be important to include measures of earlier CP because the incidence of CP is likely to decrease as children grow older and can defend themselves against their parents. Third, the variables CP and positive parenting are not included at Time 2 . Thus, future studies should include these variables at Time 2 with the aim of studying the possible reciprocal relationships between these variables and CPA.

The results demonstrate that $\mathrm{CP}$ plays a negative role in the behavior of children towards their parents even when this occurs in a positive parenting context. Preventive interventions should inform and sensitize families concerning the negative consequences of CP. Additionally, families should be provided with adaptive strategies of conflict resolution and discipline. Furthermore, the findings highlight the importance of positive educational practices that do not involve the use of physical punishment. Therefore, strategies based on monitoring and control, such as positive reinforcement of appropriate behavior and the use of non-aversive punishment (e.g., penalty task, restorative behavior and deprivation of privileges) (Straus \& Fauchier, 2007), and the adequate management of parental attention can contribute to the prevention of CPA.

1403-1420. doi: 10.1111/j. 1467-8624.2009.01341.x [PubMed: 19765008]

Brezina, T. (1999). Teenage violence toward parents as an adaptation to family strain: Evidence from a national survey of male adolescents. Youth \& Society, 30(4), 416-444. doi: 10.1177/0044118X99030004002

Byrne, B. M. (2006). Structural equation modeling with EQS. Basic concepts, applications, and programming. New Jersey: Lawrence Erlbaum Associates.

Calvete, E. (2008). Una introducción al análisis de moderación y mediación: aplicaciones en el ámbito del estrés. Ansiedad y Estrés, 14(2-3), 159-173.

Calvete, E., Gámez-Guadix, M., \& Orue, I. (2014). Características familiares asociadas a violencia filio-parental en adolescentes. Anales de Psicología, 30(3), 1776-1182. doi: http://dx.doi.org/10.6018/analesps.30.3.166291 
Calvete, E., Gámez-Guadix, M., Orue, I., González-Diez, Z., López de Arroyabe, E., Sampedro, R., ... Borrajo, E. (2013). Brief report: The Adolescent Child-to-Parent Aggression Questionnaire: An examination of aggressions against parents in Spanish adolescents. Journal of Adolescence, 36, 1077-1081. doi:10.1016/j.adolescence.2013.08.017

Calvete, E., Orue, I., \& Sampedro, R. (2011). Violencia filio-parental en la adolescencia: características ambientales y personales. Infancia y aprendiraje, 34 (3), 349-363. doi: 10.1174/021037011797238577

Calvete, E., Orue, I., Gámez-Guadix. M., \& Bushman, B.J. (2015). Predictors of Child-to-Parent Aggression: A 3-Year Longitudinal Study. Developmental Psychology 51(5), 663-676. doi: 10.1037/a0039092

Calvete, E., Orue, I., Gámez-Guadix, M., Del Hoyo-Bilbao, J., \& López de Arroyabe, E. (2015). Child-to-parent violence: An exploratory study of the roles of family violence and parental discipline through the stories told by Spanish children and their parents. Violence and Victims, 30(6), 935-947. doi: 10.1891/0886-6708.VV-D-14-00105

Red de Universidades Valencianas para el fomento de la Investigación, el Desarrollo y la Innovación (RUVID) (2013). El castigo físico, una práctica socialmente aceptado Retreived from http:/ /inforuvid.com/index.php?edi $=2135 \& \operatorname{con}=3949 \& \sec =3$

Coogan, D. (2011). Child-to-parent violence: Challenging perspectives on family violence. Child Care in Practice, 17, 347-358. doi: 10.1080/13575279.2011.596815

Cottrel, B. (2005). When teens abuse their parents. Halifax, Nove Scotia: Fernworod Publising.

Cottrell, B., \& Monk, P. (2004). Adolescent-to-parent abuse. A qualitative overview of common themes. Journal of Family Issues, 25(8), 1072-1095. doi: $10.1177 / 0192513 \mathrm{X} 03261330$

EFE (International News Agency) (2009). Las agresiones de hijos a padres se doblan en dos años, el $40 \%$ de chicas. Extraído el 21 de Noviembre de $2009 \quad$ desde http://www.elmundo.es/elmundo/2009/11/21/espana/1258797217.h $\mathrm{tml}$

Ferguson, C. J. (2013). Spanking, corporal punishment and negative longterm outcomes: A meta-analytic review of longitudinal studies. Clinical Psychology Review, 33, 196-208. doi:10.1016/j.cpr.2012.11.002

Frazier, P. A., Tix, A. P., \& Barron, K. E. (2004). Testing moderator and mediator effects in counseling psychology research. Journal of counseling psychology, 51(1), 115. doi: 10.1037/0022-0167.51.1.115.

Gámez-Guadix, M., \& Calvete, E. (2012). Violencia filio-parental y su asociación con la exposición a la violencia marital y la agresión de padres a hijos. Psicothema, 24(2) 277-283.

Gámez-Guadix, M., Jaureguizar, J., Almendros, C., \& Carrobles, J. A. (2012). Family socialization styles and child-to-parent violence in Spanish population. Psicología Conductual, 20, 585-602.

Gámez-Guadix, M., Orue, I., Calvete, E., Carrobles, J.A., Muñoz-Rivas, M., \& Almendros, C. (2010). Psychometric properties of the Spanish version of the Dimensions of Discipline Inventory (DDI) in university students. Psicothema, 22, 151-156.

Gámez-Guadix, M., Straus, M. A., Carrobles, J. A., Muñoz-Rivas, M. J., \& Almendros, C. (2010). Corporal punishment and long-term behavior problems: The moderating role of positive parenting and psychological aggression. Psicothema, 22(4), 529-536.

Gámez-Guadix, M., Straus, M.A., \& Hersberguer, S. (2011). Childhood and adolescent victimization and sexual coercion and assault by male and female university students. Deviant Behavior, 32, 712-742.

Gershoff, E. T. (2002). Corporal punishment by parents and associated child behaviors and experiences: A meta-analytic and theoretical review. Psychological Bulletin, 128, 539-579. doi: http:/ /dx.doi.org/10.1037/0033-2909.128.4.539

Gottfredson, M. R., \& Hirschi, T. (1994). A general theory of adolescent problem behavior: Problems and prospects. Hillsdale, NJ, England: Lawrence Erlbaum Associates, Inc.

Grupo de trabajo de la Sociedad Española de Epidemiología y de la Sociedad Española de Medicina de Familia y Comunitaria. (2000). Una propuesta de medida de clase social. Atención Primaria, 25, 350-363. doi:10.1016/S0212-6567(00)78518-0
Harbin, H. T., \& Madden, D. J. (1979). Battered parents: A new syndrome. The American Journal of Psychiatry, 136, 1288-1291. doi: http://dx.doi.org/10.1176/ajp.136.10.1288

Harper, F. W. K., Brown, A. M., Arias, I., \& Brody, G. (2006). Corporal punishment and kids: How do parent support and gender influence child adjustment? Journal of Family Violence, 21, 197-207. doi: 10.1007/s10896-006-9018-2

Holmbeck, G. N. (1997). Toward terminological, conceptual, and statistical clarity in the study of mediators and moderators: examples from the child-clinical and pediatric psychology literatures. Journal of Consulting and Clinical Psychology, 65(4), 599. doi: http://dx.doi.org/10.1037/0022006X.65.4.599

Hong, J. S., Kral, M. J., Espelage, D. L., \& Allen-Meares, P. (2012). The social ecology of adolescent-initiated parent abuse: a review of the literature. Child Psychiatry and Human Development, 43, 431-454. doi: 10.1007/s10578-011-0273-y

Hu, L., \& Bentler, P. M. (1999). Cut off criteria for fit indexes in covariance structure analysis: Conventional criteria versus new alternatives. Structural Equation Modeling, 6, 1-55. doi: 10.1080/10705519909540118

Ibabe, I. (2015). Predictores familiares de la violencia filio-parental: el papel de la disciplina familiar. Anales de psicología, 31(2), 615-625. Doi: 10.6018/analesps.31.2.174701

Ibabe, I., Jaureguizar, J., \& Bentler, P. M. (2013). Risk factors for child-to parent violence. Journal of Family Violence, 28(5), 523-534. doi: 10.1007/s10896-013-9512-2.

Jaureguizar, J., Ibabe, I., \& Straus, M. A. (2013). Violent and prosocial behavior by adolescents toward parents and teachers in a community sample. Psychology in the Schools, 50(5), 451-470. doi: 10.1002/pits.21685.

Larzelere, R. (2000). Child outcomes of nonabusive and customary physical punishment by parents: An updated literature review. Clinical Child and Family Psychology Review, 3, 199.

National Statistics Institute of Spain (2011). Socioeconomic levels 2010. Retrieved from www.ine.es

Omer, H. (2004). Nonviolent Resistence. A New Approach to Violent and SelfDestructive Children. Cambridge (UK): Cambridge University Press.

Pagani, L., Tremblay, R., Nagin, D., Zoccolillo, M., Vitaro, F., \& McDuff, P. (2004). Risk factor models for adolescent verbal and physical aggression toward mothers. International Journal of Behavioral Development, 28(6), 528-537. doi: 10.1080/01650250444000243

Pagani, L., Tremblay, R., Nagin, D., Zoccolillo, M., Vitaro, F., \& McDuff, P. (2009). Risk factor models for adolescent verbal and physical aggression toward fathers. Journal of Family Violence, 24(3), 173-182. doi: 10.1007/s10896-008-9216-1

Paterson, R., Luntz, H., Perlesz, A., \& Cotton, S. (2002). Adolescent violence towards parents: maintaining family connections when the going gets tough. Australian and New Zealand Journal of Family Therapy, 23, 90 100. doi: 10.1002/j.1467-8438.2002.tb00493.x

Paolucci, E. O., \& Violato, C. (2004). A meta-analysis of the published research on the affective, cognitive, and behavioral effects of corporal punishment. The Journal of Psychology, 138, 197-221. doi: 10.3200/JRLP.138.3.197-222

Peek, C. W., Fischer, J. L., \& Kidwell, J. S. (1985). Teenage violence towards parents: a neglected dimension of family violence. Journal of Marriage and the Family, 47, 1051-1058. doi: 10.2307/352350

Ripoll-Núñez, K. J., \& Rohner, R. P. (2006). Corporal punishment in crosscultural perspective: Directions for a research agenda. Cross-Cultural Research: The Journal of Comparative Social Science, 40, 220-249. doi: $10.1177 / 1069397105284395$

Robinson, P. W., Davidson, L. J., \& Drebot, M. E. (2004). Parent abuse on the rise: A historical review. American Association of Behavioral Social Science (Online Journal), 7, 58-67.

Romero, F., Melero, A., Cánovas, C., \& Antolín, M. (2007). Violéncia dels joves en la familia. Barcelona. Centre d'Estudis Juridics i Formació Especialitzada (Justícia I Societat, 28).

Simons, R. L., Simons, L. G., \& Wallace, L. E. (2004). Families, delinquency, and crime: Linking society's most basic institution to antisocial behavior. Los Angeles, CA: Roxbury. 
Straus, M. A. (2001). Beating the devil out of them: Corporal punishment in American families and its effects on children. New Brunswick, NJ, US: Transaction Publishers.

Straus, M. A. (2008). The special issue on prevention of violence ignores the primordial violence. Journal of Interpersonal Violence, 23, 1314-1320. doi: $10.1177 / 0886260508322266$

Straus, M. A., Sugarman, D. B., \& Giles-Sims, J. (1997). Spanking by parents and subsequent antisocial behavior of children. Archives of Pediatric and Adolescent Medicine, 151, 761-767. doi:10.1001/archpedi.1997.02170450011002
Straus, M. A., \& Fauchier, A. (2007). Manual for the Dimensions of Discipline Inventory (DDI). Durham, NH: Family Research Laboratory, University of New Hampshire. En http://pubpages.unh.edu/ mas2/.

Ulman, A., \& Straus, M. A. (2003). Violence by children against mother in relation to violence between parents and corporal punishment by parents. Journal of Comparative Family Studies, 34(1), 41-60.

Walsh, J. A., \& Krienert, J. L. (2007). Child-Parent Violence: An empirica analysis of offender, victim and event characteristics in a national Sample of Reported Incidents. Journal Family Violence, 22(5), 563-574. doi: 10.1007/s10896-007-9108-9

(Article received: 24-05-2016; revised: 25-11-2016; accepted: 25-01-2017) 